\title{
Promoting Motivational Awareness through the Eclectic Approach in Literacy Classes: The Case of Fourth year ENS Students of English
}

\author{
Dr. Maroua Rogti
}

Teachers Higher College of Laghouat, Department of English, Street of Martyrs, postal box: 4430, Laghouat, Algeria m.rogti@ens-lagh.dz

\begin{abstract}
Teaching literature has been an essential part of English as a subject in the language classroom which grants high culture and thought. This indeed made literature an existing issue in the language teaching paradigm. Language teachers and educationalists have implemented several potentials of examining literary texts for the benefit of the language learner. This mixed methods study aimed at examining the use of the eclectic approach along with the traditional use of literature as a source for language learning, and how it affects the learners' motivational awareness in learning a literary text in class by being literary competent. The study tempted to distribute a questionnaire for three teachers of literature to further elicit their views about certain issues, in addition to a questionnaire for a sample of 24 students at ENS of Laghouat to gather their views about the use of this approach. The major findings of the study exposed that moststudents highly received motivational awareness through the suggested classroom methodology.
\end{abstract}

Keywords-Literacy teaching; Eclecticism; Algerian EFL Context; Literary competence; Motivation.

\section{INTRODUCTION}

Teaching learners who have another language along with English can be hard even when teaching sensible subjects as physics and math. Since the advent of the Communicative Language Teaching and the fact that language is best used for communicative purposes, the communicative task has embarked to a prominence place as anissue in syllabus design. The appearance of the Eclectic Approach has led to multiple explanations of what exactly makes a task for task-based syllabuses. According to the experience of certain scholars of English literature, it is worth mentioning that the majority of EFL learners find sympathetic obstacles to understand, and analyze literature though they have been studying it since their first time to join the higher college. Besides, general dissatisfaction with literature teaching and learning in Algerian higher education especially training colleges which are basically designed for teaching has prevailed in this study as to wonder whether these impediments are due to a lack of motivation or a defect in the teaching approaches. Thus, this study aims to examine the effects of the Eclectic Approach in teaching literature and how it can contribute to enhancing the EFL learners' motivational awareness and performance in the classroom.

\section{REVIEW OF RELATED LITERATURE}

Since their inception, language teaching methods are continuously changing to adhere for the novelties brought to the domain, whether in favor of the teacher, the students, or the course itself Dweik (1986, p, 42). Such growing demands led to a successive string of needs for an efficient method that can cater for all the students and their linguistic and communicative needs at once. Because it is thought that there is no one method appropriate to teaching all the aspects of a foreign language, it has been suggested that teachers can adopt some elements from different teaching methods and integrate them within one approach. The approach has been given the name Eclecticism, and is said to be a selective tool to tailor the course objectives to the lesson needs.

According to the Oxford Dictionaries, the term Eclecticism refers to the process of deriving from different styles and varieties of ideas or sources in fulfilling a given task to achieve a particular goal. In another sense, eclecticism is the combination of skills, techniques, and knowledge that all lead to the same objective to be accomplished. Throughout the history of language teaching, there has been a significant search for effective ways of implementing foreign languages. (Perregaard, 2018, p, 39; Ro,2016, p, 39) This fact is still convenient especially in the field of TEFL as the English language has spread to the extent of being a worldwide language 
whether in education or other domains. In this regard, Atkinson (1988) asserts that:

Eclectic is one of the buzz words in TEFL at present, in part due to the realization that for the foreseeable future good language is likely to continue to be based more on common sense, insights drawn from classroom experience, informed discussion among teachers, etc., that on any monolithic model of second language acquisition or all-embracing theory of learning. (p. 42)

In that, the choice for better language teaching methods is basically the result of what previous teachers have experienced in their classrooms and not what the principles imply to be appropriate or successful. Because most teachers find it difficult to follow or adopt a specific method of language teaching, it is thought that some parts of different methods can be gathered to teach the same function (Prabhu, 1990, cited in Larsen- Freeman, 2000, p. 182) Correspondingly, Larsen-Freeman (2000) claims that, "When teachers who subscribe to the pluralistic view of methods pick and choose from among methods to create their own blend, their practice is said to be eclectic" (p. 183). That is, teachers cannot use all the methods designated for teaching TEFL in one lesson or part of a lesson. Consequently, they can select what they presume is relevant to this lesson from each method in a way that reflects eclecticism. (Kennedy, 1985, pp., 93-100)

\section{RESEARCH QUESTIONS AND HYPOTHESES}

The current study is designed to answer a set of questions related to teaching English literature. Thus, the aims of this scrutiny are guided by the following research questions:

1. To what extent can the Eclectic Approach affect Algerian EFL learners' motivational awareness in learning a literary text in the class?

2. How can teachers of literature satisfy their learners' needs through the implementation of the Eclectic Approach in teaching a literary text?

A set of hypotheses can be put forward on the basis of the previously formulated questions:

1. The motivation of EFL learners can be extremely enhanced in response to using the eclectic approach to teach a literary text.

2. Teachers of literature may succeed in using suitable methods for the sake of developing their learners' and motivational awareness.

\section{METHODS AND MATERIALS}

In order to validate and support the above stated hypotheses, the researcher conducted an empirical research at ENS of Laghouat with fourth year students. The sample is composed of 24 students who are aged between 22 and 24 who have a literature class two sessions per week. They were taught a dramatic text through an Eclectic teaching Approach in class. After the lecture is done by the teacher (the researcher herself), a questionnaire was addressed to them to elicit information in order to validate the research questions and hypotheses of the study. Another questionnaire is designed for teachers to elicit their views about the use of the eclectic approach in teaching literary texts.

\subsection{Instruments}

The researcher has opted for varied research tools for the sake of gaining enough and appropriate data in the investigation of both teaching a literary text through the eclectic approach and the attitudes and responses of learners towards the teaching methods used by teachers. In fact, since data can be collected through more than one research instrument, the researcher managed to use a questionnaire for both students and teachers. Therefore, using a case study research through which she can be conductive to the rigidity of the research design and lead us to adequate discussion and interpretation of the findings.

The questionnaire is a valid research instrument for obtaining worthy information from participants. "A questionnaire is an instrument for the collection of data, usually in written form consisting of open and/or closed questions and other probes requiring a response from the subjects" (Nunan, 1992, p. 231) using such an instrument can make the data collected easy to be analyzed, may result in reliable data and valid conclusion.

In this study, some questions are a bit broad so that the participants can shape the meaning of a situation that is ideally rigged in interactions with other people. Openended questions are more likely used "the more-openended the questioning, the better, as the researcher listens carefully to what people say or do in their life setting" and "qualitative researchers seek to understand the context of setting of the participants through visiting this context and gathering information personally" (Creswell, 2007, pp. 0809)

For, in order to collect the necessary data for our study, a variety of research approaches are used for the aim of validating and verifying the problem, questions, and hypotheses of the research. First, due to its empirical nature which is often conducted in classroom contexts, our study uses the qualitative approach because it focuses on a specific local context. Data in our study is typically based on a questionnaire and observation which usually 
characterize a qualitative case study research. (Merriam, 1998, p.39)

Qualitative research is often descriptive and it can be used when exploring a phenomenon without recognizing major variables needed to examine. Creswell (2007) claims: "a qualitative approach is appropriate to use to study a research problem when the problem needs to be explored; when a complex detailed understanding is needed; when the researcher wants to write in a literary flexible style; and when the researcher seeks to understand the context or settings of participants (p.51) Qualitative research design is an interpretive inquiry in which the researcher interprets what he sees, hears, and understands from the knowledge claims adapted. These interpretations are closely linked to the researcher's background and after setting the research; readers and participants also give their interpretations of the study. (Flick, 2013, pp.19-20)

However, our study also makes use of the quantitative approach; that is we seek to mix both approaches the qualitative and quantitative approaches of research to determine the research design and methodology through triangulation data sources in collecting and analyzing data. Thus, the research instruments, methods, and strategies of inquiry we adopt for the study will uncover the results and findings of the questionnaire and classroom observation.

To reach the analysis process, the researcher tempts to identify themes, and then conduct an inquiry of certain aspects for interpreting the results through either peer reviewing or triangulation. (Kawulich, p, 104) Our study makes use of mixed-methods approach in analyzing data. Johnson et al. (2007) defines it as: "the type of research in which a researcher or team of researchers combines elements of qualitative and quantitative research approaches (e.g., use of qualitative and quantitative viewpoints, data collection, analysis, inference techniques) for the broad purposes of breadth and depth of understanding and corroboration" (cited in. Almalki 2016, p.04)

Jick (1979) argues that researchers collect and analyze both qualitative and quantitative data in a sequential, simultaneous, or rigorous manner which integrates both types of data; they claim that the way in which this data is combined will depend upon the nature of the inquiry and the philosophical view of the researcher. Ideally, the integration of both qualitative and quantitative approaches in our research using pragmatic knowledge claims; as pragmatism allows the researcher to use different methods, paradigms, assumptions as well as different forms of data collection and analysis in conducting a mixed methods research. Yin (2014, pp.1948)

This can help in understanding the research problem. "Mixed methods approach is one in which the researcher tends to base knowledge claims on pragmatic grounds. It employs strategies of inquiry that involve collecting data either simultaneously or sequentially to best understand research problems." (Creswell 2003, p.18) In our study, we are using both qualitative and quantitative approaches to generalize the findings to a population.

\section{RESULTS AND DISCUSSION}

Data gathered from questionnaire items were analyzed quantitatively by adopting graphs and tables for the sake of displaying results. Seemingly, data gathered from Q.1 showed that the majority of students attributed the possibility of their learning progress to either the instructional materials implemented by their teachers, or the classroom setting the course takes part of. On the other hand, only six students thought that the teachers' strategies and methods of implementing the course can enhance their motivation in learning literature.

\begin{tabular}{|c|c|c|c|}
\hline Item & $\mathrm{N}^{\circ}$ & Percentage & \\
\hline Teaching Approa & & 6 & $30 \%$ \\
\hline Classroom envirc & nment & 8 & $40 \%$ \\
\hline Teaching Materia & & 10 & $50 \%$ \\
\hline
\end{tabular}

The findings collected from Q.2 illustrated that the majority (12 out of 20) said that motivation plays a major role in students' learning failure, almost half of the students attributed this failure to their inability to control their behaviors in the classroom, whereas a minority (04 out of 20) attributed the condition to their lack of interest. In fact, this provides a positive impression that most students are interested in learning literature, but the course and some underlying factors like teaching methods and quality of the text.

Table.2: What can impede your literary competence in learning literature?

\begin{tabular}{ccc}
\hline Item & $\mathrm{N}^{\circ}$ & Percentage \\
\cline { 1 - 2 } Motivation & 12 &
\end{tabular}




$\begin{array}{llc}\text { Lack of Interest } & 04 & 10 \% \\ \text { Self-control } & 08 & 40 \%\end{array}$

The learners were asked about the teaching and learning process. Most of the learners (10 out of 24) claimed that it was systematic, (9) further majority said it was not satisfying, and (5) students said it was unique as shown in table 3 . The third question aimed at asking the students about their motive for the activities used for learning a literary text.

Chart 03: The Teaching and Learning Process

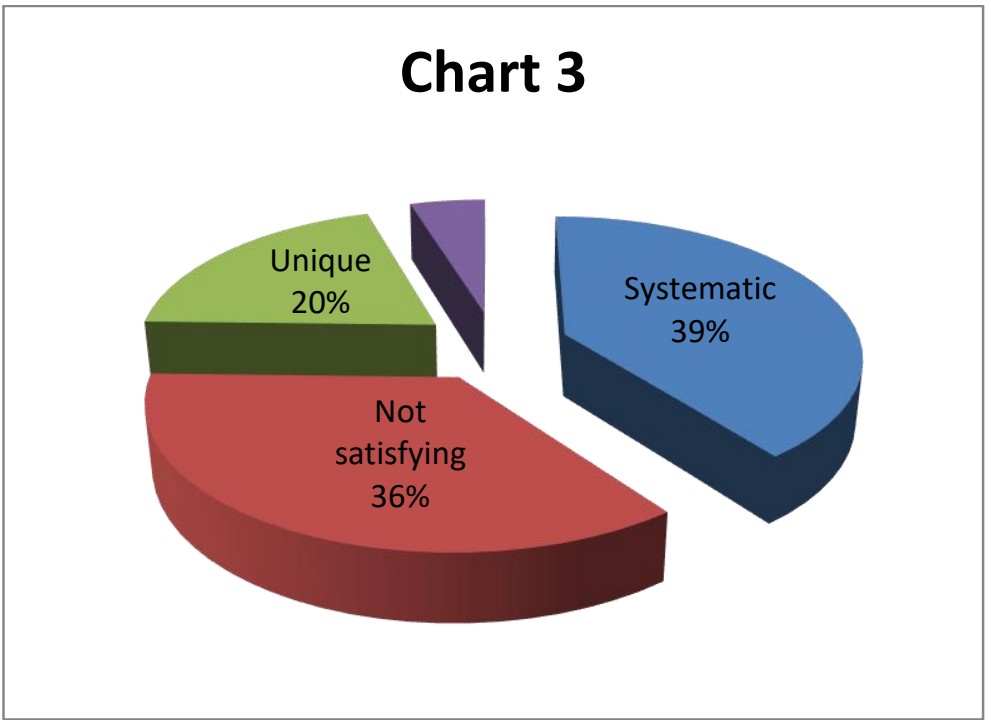

The answers varied and the majority was not satisfied with the activities used in class (10). Some considered them as interesting (8), others claim that they are quite-teacher-centered (4), and just (2) students consider them as learner-centered. As shown in chart 04

Chart 4: The activities used in the literature class

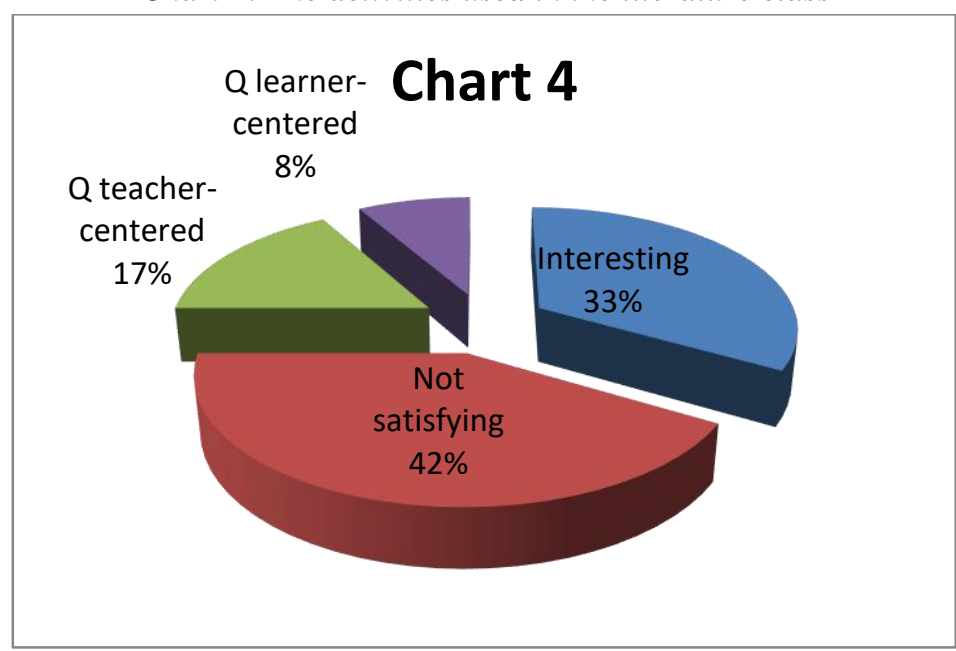

The next question asked to students was typically about the effect of approach used by teacher to learn about a dramatic text and the materials used in class. The majority of the students ( 09) asserted that they didn't have chance to express themselves in class, a further majority (6) claimed that they have been encouraged to read more dramatic texts at home, (5) enjoyed approaching drama from a distinctive angle, (3) of the students viewed it as creative, and just (1) student claimed that is motivating.

Table.5: Teaching Approach and Materials used in Class

$\frac{\text { Table.5: Teaching Approach and Materials used in Class }}{\text { Item }}$
Percentage \%
I didn't have enough chance to express myself $09(38 \%)$

I have been encouraged to read more dramatic texts at home $06(27 \%)$

$$
\text { I enjoyed approaching drama from a distinctive angle } 05(19 \%)
$$


Creative and Motivating $04(14 \%)$

The aim of the fourth question was to collect students' impressions about performance in class and acting roles done by their colleagues in class. The result was that the approach used was beyond most of the students' level. The overwhelming majority considered learning literature through eclecticism as interesting and enjoyable and just few of the students said that is boring, while (0) of the students viewed it as not enjoyable.

Table.6: General Impressions about Learning through the Eclectic approach

\begin{tabular}{|c|c|}
\hline Item & ercentage $\%$ \\
\hline Boring & $17 \%$ \\
\hline Interesting & $41 \%$ \\
\hline Enjoyable & $42 \%$ \\
\hline Not enjoyable & $00 \%$ \\
\hline
\end{tabular}

The rational of the fifth question was to ask students whether they agree or disagree with the idea that the eclectic approach as a teaching pedagogical tool can promote general education of the student and develop their literary competence. The answers were nearly similar. In this regard, most of the students agreed that this approach can contribute to developing learners' literary competence as introduced in table 07.

Table.7: The Eclectic Approach role in promoting literary competence

\begin{tabular}{lcccc}
\hline & Agree & s. agree & Disagree & s. disagree \\
\hline $\begin{array}{l}\text { Using literary notions to interpret the story } \\
\text { Appreciating the value of the different features }\end{array}$ & $18(78 \%)$ & $4(18 \%)$ & $1(04 \%)$ & $0(0 \%)$ \\
Of the literary text & & $7(30 \%)$ & $0(0 \%)$ & $0(0 \%)$ \\
Producing personal response to the text & $16(70 \%)$ & $7(30 \%)$ & $0(0 \%)$ & $0(0 \%)$ \\
$\begin{array}{l}\text { Developing critical readings of the text } \\
\text { Relating literature, language and culture }\end{array}$ & $15(63 \%)$ & $6(29 \%)$ & $2(8 \%)$ & $0(0 \%)$ \\
\hline
\end{tabular}

The focus of this question was to investigate whether performance can motivate students and their answer varied. 11 informants acknowledged that performance improves their speaking skills. A number of students (6) claimed that it increases their competence; only (2) said that it develops their English language, while (6) thought it makes them more familiar with the culture of English speaking people.

Table 08: The impact of performance on students in class

\begin{tabular}{c}
\hline Item Percentage \% \\
\hline Improving your speaking skills $11(54 \%)$ \\
Increasing your communicative competence06 (30\%) \\
Developing your English language $02(10 \%)$
\end{tabular}

Making you more familiar with the culture $\quad 06(06 \%)$

of English speaking people.

The first question was about how do teachers acknowledge the use of the Eclectic approach in teaching literature. Data gathered from Q.1 demonstrated that the majority (2 out of 1) thought that Algerian teachers of literature have fair knowledge concerning eclecticism, while the minority (1 out of 2) assumed that their knowledge is somewhat poor. Such findings illustrated that the questionnaire informants relied on their experiences in answering the question, and did not relate to other's knowledge in this area.

Table.9: The Eclectic Approach in Teaching Literature

\begin{tabular}{cc}
\hline Item & \multicolumn{2}{c}{ Percentage \% } \\
\hline Good & $/$ \\
Intermediate & $02(80 \%)$ \\
Poor & $01(20 \%)$
\end{tabular}

Q.2 is an open-ended question which attempted to eclectic approach; this addressed literary genres. The illustrate the teachers' preferences in terms of using the teachers' answers to this question were almost the same, 
where the majority said that all literary genres should be taught through eclecticism.

In the next open-ended question, the teachers were asked which method of teaching literature they thought was more effective as part of eclecticism. Data received from this question showed that the majority have chosen the Audio Lingual Method to be efficient in literature teaching, whereas only minorities have selected the other methods. These results implied that Algerian EFL teachers focused on grammatical function other than meanings and notions, the fact that has been arrived at in the first section of the questionnaire. This may justify their choice of the ALM that is typically based on drilling learners to practice grammatical structures of the target language.

The separate analysis of the results arrived at in this research has guided us towards other conclusions that may not have been apparent at the beginning. Linking the answers of both students and teachers has shown that the processes of teaching and learning are interrelated and can be separated in neither procedure nor outcome. One of the significant inferences that can be drawn from the questionnaires' results is that both participants, teachers and students, considered the teaching methodology as critical to their fulfillment of their roles. In that, the students reckoned that one of the reasons that impeded or improved their learning was the teaching methodology. Yet, the teachers' answers illustrated that most of them followed the functional approach in devising their tasks, and even in their lesson presentations.

As it has been stated previously at the beginning of this study, the position occupied by the English literature at this stage of modernism has shaped its significance. In another sense, most study streams or professions have become more interested in incorporating Literature within their systems. This has also been supported by the students' answers in the questionnaire that most of them argued that learning literature has become a necessity as it is a bridge towards their future studies.

The major assumption our study is based on is that the eclectic approach of teaching literature may benefit EFL learners in terms of motivation and literary competence. In fact, the results arrived at in the study confirmed this assumption to a great extent. Both the teacher and students were not aware of the importance of teaching approaches and methodologies. Yet, by the end of the fieldwork, they discovered that the teaching approach is a pillar upon which the whole process is built. One of the deductions that were made after data analysis is that the eclectic approach provided great opportunities for the students to express themselves and learn literature.

This can be concluded from the students' answers to the question that addressed the most relevant method of
TEFL. Most students selected the CLL and CLT as more convenient to their learning needs. This can be attributed to the fact that these two methods of learning consider the process a journey that is not confined by authorities, and that has to be fulfilled for the learner and from the learner as well. One of the great qualities that may cause the learners to select the CLT and CLL methods is that they consider the learners "whole persons" and not just passive beings to be filled with knowledge. In contrast, they are participants in the learning of language, and they discussed and consulted what is to be learnt and how to be achieved.

Throughout this study, we have attempted to show that the eclectic approach in teaching literature can contribute to improving EFL learners' competency and change their motivation levels. This could not have been achieved without following an organized plan that was based on previous literature and other findings in the same area of research. The relationship between this approach of literature teaching and the students' competency is based on the fact that the eclectic approach is designated to enhance EFL learners' acquisition of foreign languages on the one hand, and get them more involved in their learning by establishing an inter- cultural sphere with the other culture through reading literary texts.

\section{CONCLUSION}

Teaching a literary text through an Eclectic Approach is beneficial to increasing the learners' motivational awareness and thus leads to the development of their literary competence. Teachers of literature should be selective in delivering a lecture to their students by choosing the most appropriate approach that best fits and satisfies their linguistic, cultural, and communicative needs of learners in their language class. Arguably, we can conclude that the Eclectic Approach can enhance EFL learners' motivation and render them competent in the class. This study illustrated how the suggested approach to reading a literary text in class can contribute to the development of learners' competency and language skills, motivate them, and make them more familiar with the literary text by subsequently increasing their literary awareness in learning literature.

\section{REFERENCES}

[1] Atkinson, Paul. (1988). Ethnomethodology: A critical review. Annual Review of Sociology, 14, p, 42

[2] Baker, J \&Westrup, H. (2000) The English language teachers' handbook, London, UK: VSO.

[3] Almalki, Sami. (2016). Integrating Quantitative and Qualitative Data in Mixed Methods Research-Challenges and Benefits,Journal of Education and learning, 05 (03): p, 04 
[4] Creswell, John.W. (2003) Research Design: Qualitative, Quantitative, and Mixed Methods. USA: Sage Publications, Inc, $\mathrm{p}, 13$

[5] Creswell, John. W (2007)Qualitative Inquiry \& Research Design, UK: Sage Publications, p, 07-51

[6] Crystal, D. (1997). English as a global language, Cambridge, England, UK: Cambridge University Press

[7] De Dios, J \&Agudo, M. (2019). Which Instructional Program (EFL or CLIL) Results in Better Oral Communicative Competence? Updated Empirical Evidence from a Monolingual Context, Linguistics and Education Journal (Elsevier), 51, pp., 70-77

[8] Doff. A, \& Jones, C. (2000) Tests: Language in Use. Cambridge, England, UK: Cambridge University Press

[9] Dweik, B. (1986). Research Papers in Applied Linguistics. Hebron, Palestine: Hebron University Press, p, 42

[10] Fiske, Edward, B. (2000). Assessing learning achievement, France: UNESCO

[11] Flick, U. (2013)The Sage Handbook of Qualitative Data Analysis. USA: Sage Publications, pp, 19-20

[12] Godwin, W \& Godwin, L (1996) Understanding Quantitative and Qualitative Research Education. London, UK: Teachers College Press.

[13] Hancock. R. D \& A, B. (2006) Doing Case Study Research, Teachers College Press

[14] Jick, T.D. (1979). Mixing Qualitative and Quantitative Methods: Triangulation in Action. Johnson Graduate School of Management, 24 (4): pp.602-611

[15] Kawulich, B. (2004). Data Analysis Techniques in Qualitative Research. Georgia: State University of Georgia, p, 104

[16] Kennedy, C. (1985) Formative Evaluation as an Indicator of Student Wants and Attitudes. The ESP Journal, 04 (02), pp, 93-100

[17] Kothari, C. R. (2004). Research methodology: Methods and techniques. New Delhi, India: New Age International

[18] Larsen-freeman, D (2000). Techniques and Principles in Language Teaching, New York, USA: Oxford University Press

[19] Merriam, S.B. (1998). Case Studies as Qualitative Research, San Fransisco: Jossey-Bass, p, 39

[20] Moeller, R, K., \&Catalano, T. (2015). Foreign Language Teaching and Learning, n.p

[21] Nunan, D. (1992). Research Methods in Applied Linguistics, Oxford: Oxford University Press, p, 231

[22] Penttila, N. et al. (2019). Dis-fluency clusters in speakers with and without neurogenic stuttering following traumatic brain injury, Elsevier Journal of Fluency Disorders, 59, p, 36-37

[23] Perregaard, B. (2018). The Dynamics of Interactional and Intentional Pattern Formation in Children's Language Socialization, Elsevier, Language \& Communication Journal, 62 (05), p, 41

[24] Ro, Eunseok. (2016) Exploring teachers' practices and students' perceptions of the extensive reading approach in EAP reading classes, Elsevier, Journal of English for Academic Purposes, 22 (02), 2016, p, 39
[25] Rusk, F \& Porn, M. (2019). Delay in L2 Interaction in Video-mediated Environments in the Context of Virtual Tandem Language Learning, Elsevier, Linguistics and Education, 50, p, 56, DOI: https://doi.org/10.1016/j.linged.2019.02.003

[26] Xia, Y. (2014). Language theories and Language Teaching: From Traditional Grammar to Functionalism. Journal of Language Teaching and Research, 05 (03), 559-565.

[27] Yin, R. (2014)Case Study Research Design and Methods, Thousand Oaks, Sage Publications. $5^{\text {th }}$ ed,pp, 19-48 